\title{
Otto friedrich bollnow's concept of human space. A Critical Discussion on the Fundamentals of the Concepts of Space
}

\author{
Wasana de Silva
}

\begin{abstract}
The concepts of space and place are well recognized and accepted in recent architectural theories and practices but definitions vary according to different interpretations. The concepts of "space and place" fall within the realms of philosophy the earliest of which can be traced to those of Aristotle whose notion of space was comprised of earthly as well as cosmic dimensions and was not an undefined Cartesian concept. Much Later, Christian Norberg Schulz has proposed the concept of 'existential space' which was based on Jean Piaget's studies of a child's concept of space, (ontogenetical aspects of space conception $1963-1973$ ) 'its socio/cultural aspects, (philogenetic problem of space conception) and philosophical phenomenological studies of his time. But his studies were inspired by many previous studies like well-known historian of religion Mircea Eliade, the art historian Dagobert Frey (1949) and the philosophical phenomenologist Otto Friedrich Bollnow.
\end{abstract}

The concept of "Human Space" by O.F. Bollnow can be taken into broader discussions than the Schulz' concept of 'existential space', because, Norberg Schulz (1971) directly related concept of 'existential space' into more concrete 'architectural space' of which definitions were unclear. Therefore in the realm of Architectural research on concepts of "space and place', O. F. Bollnow's ideas of 'Man and Space' provides a fundamental basis for further critical and inspirational thinking. The intention of this paper is to reveal the idea of concept of space in Bollnow's work for further architectural research.

\section{Introduction}

O.F. Bollnow's book "Man and Space" (1963) provides a paradigm of anthropological sense of space. The book consists of five main chapters, entitled: 'The Elementary Articulation of Space', 'The Wide World', 'The House and the Feeling of Security", Aspects of Space' and 'The Spatiality of Human Life'. Unfortunately the book is not translated into English. Therefore only the fundamental thinking of Bollnow's concept of space which was co-written by other scholars has to be taken into discussion.

Bollnow's concept of human space is related to the foundations of dwellings and settlements. Therefore, it essentially relates to architecture, man and his environment. His studies are based on a wider framework of philosophical ontology, psychopathology and psychology. While human existence and spatiality is inseparable, the temporality of human existence is the central and basic philosophical problem addressed by several philosophers of his time, Bergson, (1907) Simmel (1910), Heidegger (1927), Sartre (1943), Merlau-Ponty (1945) and Minkowsky (1915). Bollnow's approach is humanistic and phenomenological as he places Man and his immediate environment at the center of everything he describes. His concept of space essentially relates to Man and his experiences which are largely confronted with the modern concept of infinite, boundless, Cartesian space, explored recently, due to new inventions in Science and Technology.

\section{Critical Discussion On The Concept Of Man and Space.}

Bollnow describes that space is not homogenous, but is articulated using various sources like Aristotle's puzzling discussion of space and interpretation of space and place in occidental traditions. Above argument denotes a kind of 'flowing quality' in space (like gas or light, although liquids are fluids not flowing through whole space). This idea can be re-evaluated as, to be articulated there should be something more in the space) other than 3D extension of empty void, things, people and their behaviour, but there is nothing in the empty void to be articulated. Things can be described as fixed objects, non fixed objects and people. But, none of these objects are articulated as they are solid objects. Therefore what is articulated in the space? Is it only the light? Or, is it a more invisible and intangible thing than light?

B Bollnow gives his own definition of space as an ambivalent 'medium' which is dialectically constructed between subject and environment between human being (physical and psychological) and environment. 'Medium dialectically constructed' means, it is not there from the beginning and it is constructed as a medium means to transmit 'something' through a medium between subject and environment. Therefore what is transmitted between subject (human) and the environment through the medium, the space? 
According to Bollnow's argument, space is not there from the beginning and space in the human sense is evolved can be taken into further discussion as, if space is not there from the beginning and evolved in human sense, what is the three dimensional void we recognize around us? Although Bollnow describes human space as not the three dimensional extension interpreted through new knowledge; the human space is demarcated by humans, their actions, objects and symbols, therefore human space is a three dimensional void filled with meanings, things and performance. But, before humans the three dimensional void is there and some of the things are there. There seems to be a certain conflict between the meaning of three dimensional void (finite or infinite space) we recognized in the space and space of human sense. But anthropological sense of space is clearly different from modern concept of space, the infinite three dimensional void. Therefore clear definitions for concepts of space and place are urgently needed in the development of architectural research.

Bollnow has taken the anthropological function of the house. According to him, 'Dwelling' means to be at home in a particular place that implies special conditions. Dwelling means to be entered and to be contented. He suggests by the etymology of German word 'raum' (word used originally to mean space), corresponding verbal form 'raumn' (Grimm) means to clear a part of the wilderness with the intention of settling down, to establish a dwelling, and means in the event of dwelling human experience the anthropological sense in the space. Therefore although a human being is there, if he is not dwelling he will not experience the anthropological sense of space, although three dimensional void, objects, behaviour and some other things exist around him. To experience anthropological space he must dwell on the earth and that means human space has more dimensions than defined physical space, objects, behaviour and people within it.

Bollnow suggests the original meaning of space as to clear a part of wilderness with the intention of settling down to establish a dwelling that implies certain conditions, entering, focusing, anchoring and clearing the things out (wilderness) to establish a psychological form. Centered, entered and kept wilderness out, implies exact opposite situation of cosmic space (infinite, boundless and diverging three dimensional extensions. In the event of dwelling human being is entering into the opposite direction of diverging space extension, which space is converging into the center, denotes he has gone beyond the physical dimension of space by the establishment of "Human Space", because if physical space is diverging towards infinity, psychological space must be converging towards infinity of subjective inside.

Bollnow's concept of human space concept is expressed by polar relations, two opposite experiences. He describes fixed points and zero points in the concept of human space. Fixed points as hereditary spaces (home) and zero points as hotel rooms in foreign cities. Accordingly fixed points imply dwelling means experience of polar relation. Then what is the experience in zero points? Is it not fixed, not entered, not dwelling and non human sense of space?

Bollnow points out that hierarchical systems of markers for central points (dwellings, churches/ markets, centers of cities and states) and he describes ancient interpretations of such fixed points as marking the 'center of the world' or the 'axis mundi. In the wide concept of physical space or in the anthropological concept of physical space, there is no such center of the world, which is physically existed. But by marking central points in the event of dwelling and interpretation of such fixed points as centers of the world or 'axis mundi', denotes experience of one center by every one in the human space. As discussed in the event of dwelling human being is focused, entered and kept thing out (wilderness) denotes experience of total opposite side of wide physical space (infinite, boundless and diverging). The 'axis mundi' or the 'center of the world' creates special center, which makes everything converging inside, to a one center, which is not existing in the physical domain but in the psychological domain.' In this psychological domain every one who is dwelling experiences one center. Therefore human space does not only exist in the physical space; it exists in exact opposite experience of physical space as described by Bollnow. 'Anthropological space is expressed in polar relations' means two opposite experiences. Therefore term 'space' is questionable according to our interpretation of concept of space.

Bollnow describes that space is produced by force of love. 'Creation of space through the force of love', living together of lovers does not increase space in terms of quantity, lovers share the same space. They create a home for themselves that denotes kind of revelation of non physical dimensions of space, means spatial concept of human space comprise physical and opposite experience of physical dimensions.

Bollnow describes the archaic concept of space related to the foundation of dwelling and settlements and presents three domains of dwelling: BODY, HOUSE AND OPEN SPACE. According to Bollnow, Human being is at the center of space and experiences human space at body level within inside corners and nooks of the dwelling, inside the dwelling and experiences human space in open spaces which are as centers of whole villages. That means human space can be 'enlarged' and 'contracted' in the physical domain and in the lovers case it is enlarged in the psychological domain.

Bollnow plausibly shows that the notion of space was originally closely related to the narrow environment of the foundation of settlements and dwellings. When a human being physically dwells in the home he experiences human space and reveals the non physical dimensions of human space that means the 
anthropological sense of human space is not only physically experienced but also subjectively experienced.

Bollnow describes fixed points and centers. He also enumerates many concrete symbols related to such central fixed points such as pillars, palaces, sanctuaries, and sacred mountains in many cultures to experience the dwelling, to establish a human spatial condition. Certain fixed points, which are physically demarcated in the physical space mark centers (interpreted by ancient cultures as center of the world), and establish oppositional experience of wide three dimensional extension. Therefore the anthropological sense of center in the human space is very important, for further research areas of concept of space and place in architecture.

Unlike the English term 'center' the German word 'Mitte' does not necessarily denote the centricity of a circle. 'Mitte' can also mean half way on a linear extension or 'mitte' in the sense of threshold, for example between two fields and two rooms. Therefore the center of human space, a threshold to another field, between two opposite experiences, the wide three dimensional world, which is diverging into infinite and its opposite experience of space which is converging into center. The center opens another field and each ones center coincides in this field. But world beyond center does not exist in the physical extension, it must be in the subjective extension, as we see no more beyond center or as we can't reach beyond center within human levels.

According to Bollnow human existence is a kind of rhythm between polar contrasts, that means two opposite experiences. Hence in the event of dwelling, in defined physical space he must experience undefined non physical space, which is in the psychological domain. Thus polar contrasts are experienced by human being in subjective sense.

Bollnow has discussed kind of typology of spaces related to particular forms of human behaviour. This denotes a wide range of forms of space implied by different experiences of different behaviours, although they are getting similar experiences. (Human sense of center, polar relations, demarcating own space by keeping things out in the human space)

The human existence is a kind of rhythm between two contrasting poles. Thus one end of it is in the physical world, the three dimensional void defined by objects, people, behaviour and the other end is in the psychological and subjective world, total opposite experience of three dimensional world that is focused, entered and kept things out as interpreted by German etymology of raum' (space). If center exists in between these two domains as a threshold, then that means human beings subjectively experience at one end, while physically dwelling at the other end in the human space. Dwellings, settlements and all fixed points interpreted by ancients mark centers, the door to another domain which is subjectively entered and experienced by human beings in the anthropological space. Bollnow describes fixed points as reference points of departure in to zero points or lesser known places and coming back. But fixed points are centers or thresholds to another dimensional world which is absolutely subjective and departure in to the out side of physically demarcated space is not less known or unknown. Out side is always outside for the human space. But when a human being is moving out side from his dwelling, as he is experiencing at the center of the human space, whether the space is also moving with him? In the event of moving, as there are no fixed points or central points to be anchored, focused and kept things out and entered into another field, don't they really dwell? Do central points (physically exist) essentially need to be dwelling on the earth? All these are critical questions of further research areas in the anthropological sense of concept of space.

\section{Conclusion}

Anthropological sense of human space derived "some thing more "other than human beings, their performance, objects, semi fixed objects and three dimensional void as we recognized. This 'something' is invisible and intangible. But the anthropological sense of 'some thing' is always within the human space of dwelling. Human space reveals the non physical dimensions of space, thus it has physical dimensions as well as psychological dimensions, denoting that it not only exists in the physical world, but also exists in the psychological world. Therefore the term 'SPACE' is questionable.

The human experience of center in the human space is very vital as the doorway to the opposite field of experience, which is demarcated symbolically or spatially in the physical world of experiences but in the subjective world of experiences the center acts as a unified center for every one. Therefore within the human space the dweller is experiencing two exact opposite spatial experiences.

\section{References}

Bollnow, O.F., (1963), Mensch und Raum, Kohlhammer, Stuttgart.

Egenter, N.,(1992), Otto Friedrich Bollnow's Anthropological Concept of Space, Paper presented at the $5^{\text {th }}$ International Congress of the 'International Association for the Semiotics of Space', Hochschule der KYnste Berlin.

Egenter, N., (1992), O.F. Bollnow and the Ontology of Home and Movement Outside, Paper prepared for the symposium on 'The Ancient Home and the Modern Internationalized Home: Dwelling in Scandinavia', University of Trondheim, Norway.

Rapoport A., (1994), "A Critical Look at the Concept of "Place", National Geographical Journal of India, Vol. 40(ISSN: 00279374/1994/0926-0951) 